\title{
MAPEAMENTO DA FREQUENNCIA DE USO E CARACTERÍSTICAS DA BIOMASSA FLORESTAL UTILIZADA PARA GERAÇÃO DE ENERGIA EM LAGES, SC
}

\author{
MAPPING THE FREQUENCY OF USE AND CHARACTERISTICS OF FOREST BIOMASS USED \\ FOR POWER GENERATION IN LAGES, SANTA CATARINA STATE
}

\author{
Thielly Schmidt Furtado ${ }^{1}$ Juliana Ceccato Ferreira ${ }^{2}$ \\ Martha Andreia Brand ${ }^{3}$ Graciela Inês Bolzon de Muñiz ${ }^{4}$ Waldir Ferreira Quirino ${ }^{5}$
}

\begin{abstract}
RESUMO
A região de Lages, Santa Catarina, tem sua economia baseada na indústria de base florestal, principalmente de transformação primária, que é caracterizada pelo baixo rendimento e grande produção de resíduos, o que causa problemas ambientais, logísticos e financeiros. A utilização destes resíduos em sistemas de cogeração tem sido uma alternativa economicamente rentável, desde o ano de 2005, no local de estudo. O objetivo deste trabalho foi realizar um mapeamento da frequência de uso e disponibilidade dos resíduos de biomassa florestal utilizados na operação de uma planta de cogeração, entre 2005 e 2009, em Lages, Santa Catarina, bem como avaliar a qualidade energética deste combustível. Foram utilizados os dados do controle de qualidade mensal das propriedades energéticas da biomassa usada na geração de energia, no período de 2005 a 2009. Os resíduos foram caracterizados segundo a frequência de análises de cada tipo de biomassa e em função do teor de umidade, teor de cinza, poder calorífico superior e líquido, para a caracterização energética. O resíduo com maior disponibilidade foi a casca de Pinus, porém, os mais eficientes energeticamente foram o cavaco com casca de Pinus e a mistura de todos os resíduos usados nos sistemas de geração de energia.
\end{abstract}

Palavras-chave: cogeração; energia de biomassa; eficiência energética.

\section{ABSTRACT}

In the region of Lages, in Santa Catarina state, the economy is based on the forest industry, especially for primary processing, and this is characterized by low yields and high production of waste, constituting environmental problems, logistical and financial support. The use of biomass in co-generation systems has been an economically profitable, since the year 2005, the place of study. In this context, the aims of this study were to map the frequency of use and the availability of wood waste used for co-generating of energy in Lages, Santa Catarina, and to evaluate the energetic properties. The sample data and the results of the energetic properties of biomass samples used in a co-generating energy in the period 2005 to 2008. The residues were characterized in terms of moisture content, ash content, gross calorific value and net calorific value. The results showed that the most available residue is the pine bark, although the most energetically efficient ones were the chip with pine-bark and the mixture of all waste systems used in generating power.

Keywords: cogeneration; wood waste; energetic efficiency.

1. Engenheira Florestal, Prefeitura Municipal, Rua João Morelli, CEP 88370-000, Botuverá (PR). thielly.furtado@gmail.com

2. Engenheira Florestal, Mestranda do Programa de Pós-graduação em Rede em Bioenergia, Universidade Federal do Paraná, Av. Lothário Meissner, 3400, Jardim Botânico, CEP 80210-170, Curitiba (PR). mana.juli@yahoo.com.br

3. Engenheira Florestal, Dra., Professora do Departamento de Engenharia Florestal, Universidade do Estado de Santa Catarina, Av. Luís de Camões, 2090, Conta Dinheiro, CEP 88520-000, Lages (SC). a2mab@cav.udesc.br

4. Engenheira Florestal, Dra., Professora titular da Universidade Federal do Paraná e Coordenadora de Pesquisa e Desenvolvimento Tecnológico, Coordenadora do Programa de Bioenergia, Av. Lothário Meissner, 3400, Jardim Botânico, CEP 80210-170, Curitiba (PR). gbmunize@ufpr.br

5. Engenheiro Florestal, PhD., Analista ambiental-pesquisador do Serviço Florestal Brasileiro, Ministério do Meio Ambiente, Pesquisador Associado e Professor colaborador na Universidade de Brasília, SAIN, Av. L4 lote 4, Ed. Sede do IBAMA, Asa Norte, CEP 70818-900, Brasília (DF). waldir@ibama.gov.br

Recebido para publicação em 26/02/2010 e aceito em 5/09/2011 


\section{INTRODUÇÃO}

A indústria de base florestal no Planalto Sul Catarinense, juntamente com a agricultura e a pecuária, representam hoje a base da economia local, contribuindo com $43 \%$ do Produto Interno Bruto (PIB) regional de forma direta e com $60 \%$ do PIB regional de forma indireta. No início de sua atividade, na década de 1940, a indústria baseou-se na exploração de madeiras oriundas de florestas nativas, sendo que, a partir da década de 80 , a base florestal passou a ser as florestas plantadas, principalmente de espécies do gênero Pinus. No entanto, em ambos os casos, o setor sempre se caracterizou pela grande geração de resíduos sem destinação econômica. Estes resíduos eram estocados em depósitos a céu aberto ou simplesmente queimados ao longo do período de atuação da indústria de base florestal na região. Alguns depósitos ainda existem, constituindo problemas de ordem ambiental, logística e financeira.

Atualmente, a quantidade de resíduos gerados vem aumentando progressivamente por dois motivos: o baixo rendimento produtivo que caracteriza a atividade de transformação primária, principal representante do setor na região, e pelo aumento do número de empresas existentes, que somam mais de 300, em um raio de $120 \mathrm{~km}$ da capital regional, Lages (BRAND, 2001 e 2005).

Por outro lado, a instabilidade dos preços dos combustíveis fósseis, atrelada ao esgotamento das suas reservas, instigou a busca por fontes alternativas de energia que auxiliassem no suprimento da demanda dos setores industrial e doméstico. Deste modo, tanto os estoques de resíduos, quanto os resíduos recém-gerados, passaram a ser vistos como uma alternativa viável para a geração de energia, especialmente em sistemas de cogeração (BRAND et al., 2002).

Segundo Nogueira e Horta (2003), nos anos 90, quando a temática ambiental incorporase nas discussões sobre energia, a biomassa passa a ser considerada uma alternativa para atender à demanda energética, pois tem a vantagem de ser um combustível renovável e com baixa capacidade de poluição.

Soares et al. (2003b) ressaltam que a tendência atual é que parte das florestas plantadas siga o conceito de obtenção de multiprodutos, sendo que a geração de energia associada à produção de madeira é a opção mais rentável. Os mesmos autores (2003a) afirmam que tal procedimento representa um diferencial competitivo, pois aumenta a flexibilidade da empresa na comercialização dos produtos, propiciando a redução dos riscos de prejuízos e aumentando a rentabilidade econômica de povoamentos destinados a multiprodutos.

Sendo assim, uma opção com enorme potencial para a geração de energia a partir de biomassa seriam os modernos sistemas de cogeração, onde ocorre a geração simultânea de energia térmica e mecânica a partir de uma mesma fonte primária de energia. A energia térmica é utilizada como fonte de calor para um determinado processo, enquanto que a mecânica é convertida em trabalho ou em energia elétrica através de um gerador de eletricidade (COELHO, 1999).

No entanto, o uso da biomassa depende de uma avaliação criteriosa da quantidade disponível e de sua qualidade, além da verificação das questões de mercado que determinam outros usos concorrentes, da tecnologia disponível para o uso da mesma na geração de energia, entre outros fatores técnicos, econômicos, sociais e ambientais.

Em se tratando dos aspectos técnicos da qualidade da biomassa, deve-se considerar que suas propriedades físicas e químicas são alteradas pelo tratamento aplicado à mesma, desde a colheita até o uso final. As principais propriedades alteradas são o teor de umidade (TU), teor de cinza (TC), poder calorífico superior (PCS) e poder calorífico líquido (PCL). Logo, torna-se necessário controlar a variação destas características para a otimização do uso do material para geração de energia.

Assim, o objetivo do presente trabalho foi avaliar a qualidade e a disponibilidade temporal de diferentes subprodutos provenientes da indústria madeireira, que foram utilizados em um sistema de cogeração de energia, entre os anos de 2005 e 2009, na região de Lages, Santa Catarina, Brasil.

\section{MATERIAL E MÉTODOS}

O material analisado é o resíduo das atividades de extração e beneficiamento industrial da madeira de Pinus sp., de plantios homogêneos, na região do Planalto Sul Catarinense. As amostras não foram coletadas especificamente para este trabalho. É uma atividade rotineira de controle de qualidade do material comprado por uma cogeradora instalada em Lages. A classificação abaixo e os valores das propriedades energéticas analisadas neste trabalho foram obtidos dos relatórios mensais do controle de qualidade da biomassa utilizada na planta de 
cogeração, em Lages, durante o período de setembro de 2005 a junho de 2009.

Estes resíduos se apresentaram em diferentes formas e tamanhos: serragem recémgerada (proveniente do corte das toras nas serras de desdobro primário); cavaco (proveniente da conversão de outros tipos de resíduos como costaneiras, refilos e destopos) e casca (oriunda do descascamento de toras utilizadas em serrarias, laminadoras e fábricas de celulose e papel). As categorias de resíduos serragem e cavacos apresentavam casca, ou podiam ainda estar secos, quando oriundos da transformação secundária da madeira (fábricas de painéis, móveis, construção civil). Além dos resíduos industriais, ainda foram analisados o cavaco florestal (produzido a partir de operações florestais como desbastes e corte raso); serragem de passivo ambiental (biomassa de depósitos com aproximadamente 10 anos de estocagem a céu aberto, feitos pelas indústrias ao longo do período de funcionamento das unidades fabris) e o MIX. Este, sempre estará presente nas análises, pois é oriundo da mistura de todos os resíduos que entram na planta de geração de energia e se caracteriza como a amostra coletada no momento da entrada da biomassa no sistema de geração de energia. Também serviu como parâmetro para a análise do rendimento da planta e do fator de conversão baseado na relação MW de energia elétrica gerada/biomassa que entra no sistema de geração de energia.

As propriedades avaliadas foram: TU, TC, PCS e PCL, através das Normas NBR 14929 para teor de umidade; NBR 13999 para teor de cinza, e DIN 51900 para poder calorífico, em 870 amostras testadas durante o período de estudo. As análises foram feitas no Laboratório de Química da Madeira da Universidade do Planalto Catarinense (UNIPLAC).

Além da avaliação das propriedades energéticas da biomassa, os relatórios permitiram determinar a frequência de uso e a disponibilidade temporal dos materiais avaliados, devido à existência de dados de classificação das amostras e fornecedores. Dentre os materiais analisados, os que se destacaram quanto à disponibilidade e frequência de uso foram submetidos à análise de variância para verificar se existiam diferenças significativas para as propriedades energéticas. Os valores médios de PCS, PCL, TU e TC das amostras foram submetidos ao teste de Tukey, ao nível de $5 \%$ de probabilidade de erro, com auxílio do software Statistica. Os gráficos apresentados foram construídos no programa Excel.

\section{RESULTADOS E DISCUSSÃO}

\section{Disponibilidade e frequência de uso da biomassa para geração de energia}

No aspecto frequência de uso e disponibilidade de material, no período de setembro de 2005 a junho de 2009, destacaram-se a casca de Pinus; cavaco com casca de Pinus; serragem recém-gerada e serragem de passivos ambientais. As respectivas quantidades podem ser visualizadas na Figura 1, que mostra também a quantidade de amostras dos demais subprodutos utilizados na geração de energia na planta de cogeração.

A maior disponibilidade de casca de Pinus pode ser explicada pelo fato da casca não apresentar outra alternativa de utilização econômica na região. O mesmo ocorre com a serragem, pois, segundo Brand et al. (2004) esta apresenta altos teores de umidade e limitações para outras aplicações, que não seja a queima. Os briquetes produzidos apenas com serragem apresentam características físicas inferiores (FURTADO et al., 2010), o que dificultaria o manuseio e transporte deste em larga escala.

O cavaco com casca de Pinus também apresentou elevada oferta em relação aos demais resíduos considerados neste estudo, pois as fontes de produção são as mais variadas, desde a conversão de costaneiras, refilos e destopos. Geralmente este material é transformado em cavacos na própria indústria de conversão primária, o que facilita as operações de transporte e estocagem.

A maior parte dos cavacos utilizados para a geração de energia contém casca, pois grande parte das empresas de transformação mecânica da região não possui descascadores. Quando este equipamento está presente, as toras são descascadas antes de entrarem no processo de beneficiamento. Desta forma, se obtém o chamado cavaco limpo ou cavaco sem casca, que é destinado à produção de papel e celulose. Em termos econômicos, esta alternativa tem maior retorno, e possui mercado consumidor na região devido à existência de duas grandes indústrias de celulose e papel e uma indústria de $\mathrm{MDF}$, localizadas em um raio inferior a $50 \mathrm{~km}$ do município de Lages, onde a cogeradora está instalada.

O cavaco florestal, originário das toras colhidas nas operações florestais de desbaste e resíduos do corte raso (copa, galhos e toras de 


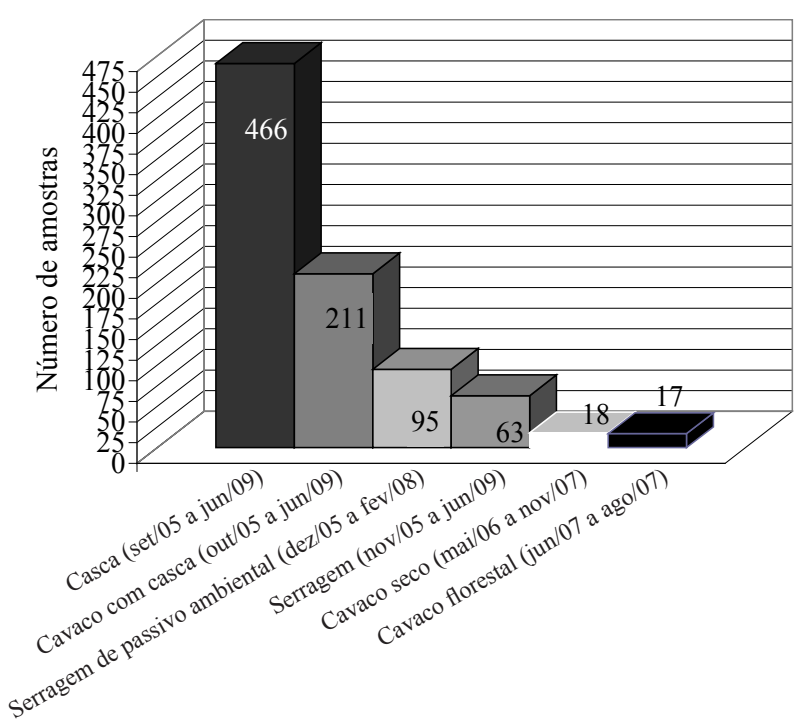

FIGURA 1: Número de amostras analisadas durante o período de 2005 a 2009, em função do tipo de resíduo, na região de Lages, SC.

FIGURE 1: Number of samples analyzed during the period from 2005 to 2009 , depending on the type of waste in the region of Lages, Brazil.

pequeno diâmetro), também é vendido para fábricas de pallets, palitos de fósforo ou painéis de partículas e fibras, o que contribui para maior variação no preço e disputa mais acirrada de mercado, apresentando uso sazonal na indústria de geração de energia.

A Figura 2 apresenta a variação da disponibilidade dos tipos de biomassa, entre setembro de 2005 a fevereiro de 2008. Analisandose ao longo do tempo, é possível observar que a casca de Pinus apresentou maior disponibilidade ao longo do período. A serragem oriunda de passivos ambientais teve maior frequência de análises entre 2006 e 2007, devido ao consumo de uma área no Município de Campo Belo do Sul, cujo estoque tinha potencial para abastecimento parcial (utilizado na mistura que entrava na caldeira) da planta por mais de 1 ano, na proporção de um terço da matéria-prima consumida mensalmente.

Houve a redução na quantidade de análises em resíduos individualizados entre outubro de 2006 até abril de 2007, sendo que apenas a análise de MIX se intensificou. Esta alteração na forma de amostragem e controle da qualidade da matériaprima para a geração de energia indica a maior preocupação da empresa em controlar e determinar a mistura ideal de biomassa, para garantir o melhor rendimento da planta, através da relação MW de energia elétrica gerada, em função da quantidade de biomassa utilizada no sistema de geração.

Neste mesmo período, a indústria florestal como um todo sofreu efeitos de uma crise econômica, que refletiu na redução da manufatura de produtos de madeira e na produção de seus resíduos. Além disso, os resíduos gerados tiveram maior demanda em outros setores da indústria, com a produção de painéis e até na indústria de produção de alimentos e bebidas instaladas na região, contribuindo para maior valorização dos resíduos no mercado e maior disputa por esta matéria-prima.

\section{Qualidade energética da biomassa utilizada para geração de energia}

Quanto ao teor de umidade (TU), a serragem apresentou o maior valor dentre todos os materiais, seguida da casca, MIX e cavaco com casca. Todos os resíduos foram estatisticamente diferentes entre si pelo teste de Tukey (Tabelas 1 e 2).

$\mathrm{O}$ banco de dados analisado forneceu a informação de que a maior parte da serragem utilizada na planta cogeradora foi oriunda dos grandes depósitos formados pelas indústrias de base florestal da região, ao longo de, pelo menos, 10 anos.

Brand (2007) estudou as alterações na qualidade energética dos resíduos de biomassa florestal, com grandes dimensões (toras e costaneiras), em função do tempo de armazenamento. A autora concluiu que o tempo ideal de estocagem para este tipo de material variou entre dois a quatro meses, devendo ser o menor possível. O tempo de estocagem deve ser suficiente somente para a redução do teor de umidade do material, sem causar perda do potencial energético, devido à degradação física, química e biológica, sofrida pela matéria seca ao longo do tempo de estocagem. A serragem de passivos ambientais sofreu biodegradação ao longo do tempo de estocagem, o que aumentou a permeabilidade da madeira e resultou em aumento na quantidade de água adsorvida. Portanto, o fator biodegradação contribuiu para que este resíduo apresentasse o maior teor de umidade entre as categorias de biomassa analisada.

A casca de Pinus, assim como a serragem, apresentou menor granulometria, teve menor massa específica e maior permeabilidade, resultando em umidade elevada.

O MIX, sendo resultado da mistura dos diversos materiais, teve TU intermediário, apresentando vantagem na sua utilização em termos 


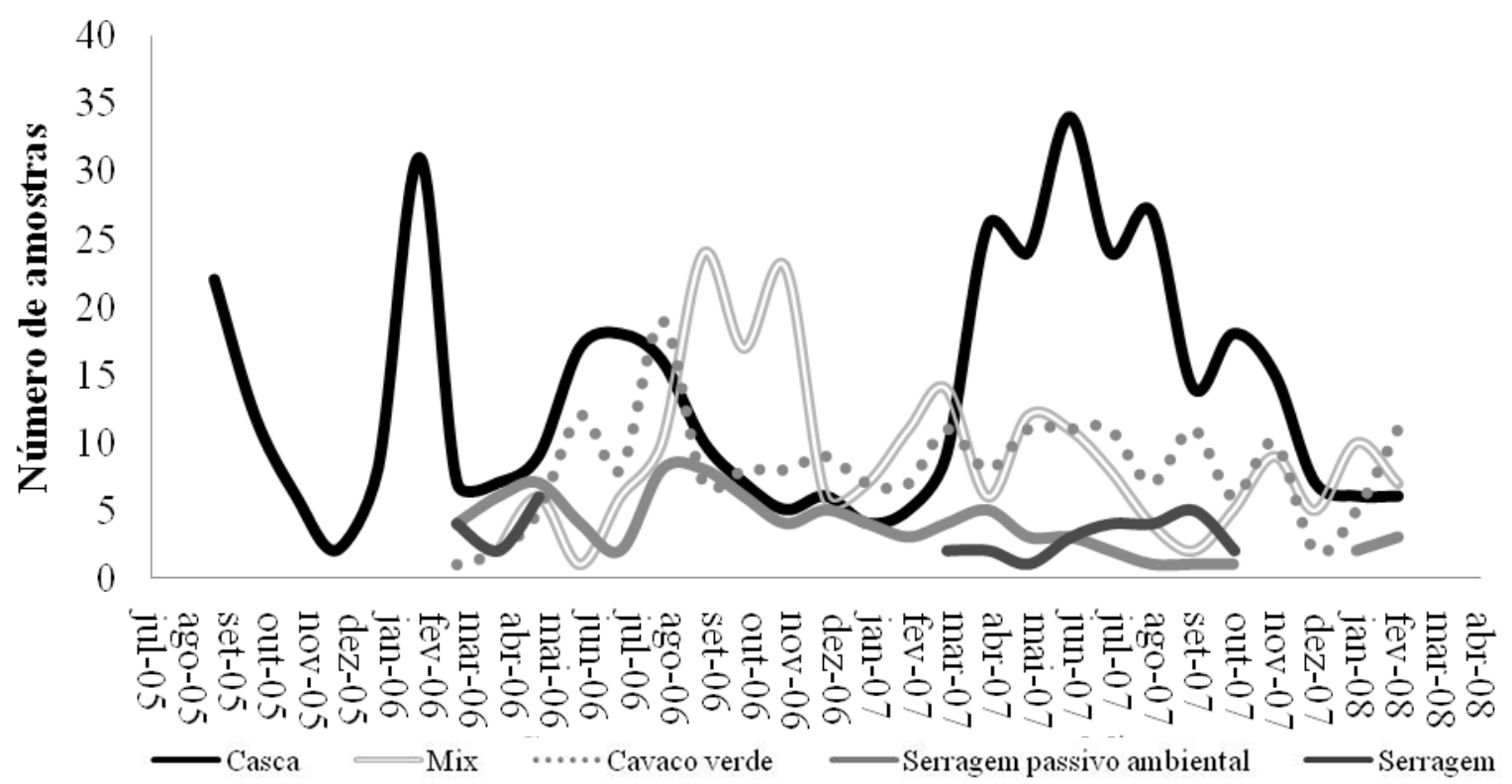

FIGURA 2: Variação da disponibilidade dos diferentes resíduos ao longo do tempo na região de Lages, $\mathrm{SC}$.

FIGURE 2: Change the availability of different residues over time around Lages, Brazil.

TABELA 1: Análise de variância global para as propriedades energéticas estudadas nos diferentes tipos de resíduos para a região de Lages, SC.

TABLE 1: Analysis of variance for the overall energetic properties studied in different types of waste to the region of Lages.

\begin{tabular}{ccc}
\hline FV & QM Erro & F \\
\hline PCL & 45892 & $37,65^{*}$ \\
PCS & 529650 & $07,08^{*}$ \\
TC & 24 & $253,67^{*}$ \\
TU & 36 & $101,51^{*}$ \\
\hline
\end{tabular}

Em que: $*=$ significativo a $5 \%$ de probabilidade de erro pelo teste $\mathrm{F}$.

de umidade. Já o cavaco com casca teve menor TU, pois se caracteriza por ter maiores dimensões em relação aos demais resíduos.

Brito e Barrichello (1979) afirmaram que a madeira recém-cortada apresenta teor de umidade variando entre 45 e $50 \%$. Os valores encontrados para TU são elevados quando comparados a esta literatura, provavelmente devido ao fato de estes materiais não terem sido abrigados de intempéries.

Em relação ao teor de cinza (TC), a casca apresentou valor significativamente superior, seguida do MIX, cavaco com casca e serragem. Os dois últimos, em termos estatísticos, são iguais entre si, porém, diferentes do MIX.

$\mathrm{O}$ teor de cinza da madeira é bastante baixo, com valores inferiores a $1 \%$ (BRITO e BARRICHELLO, 1979). Porém, já era esperado que a casca apresentasse valor superior de TC, devido a sua contaminação durante a utilização da madeira, desde a floresta até a indústria, causando incrustações de terra, pedras e outros contaminantes, elevando assim os valores desta variável neste tipo de biomassa.

O MIX também apresentou TC elevado, pois em sua constituição há a presença de casca, entretanto, não é um valor que impeça a sua utilização, ou reduza o seu potencial energético em relação aos materiais individuais.

Os valores de TC dos cavacos, MIX e serragem foram baixos e condizentes com a literatura, sendo esta uma das vantagens do uso de biomassa para geração de energia, segundo Migliorini (1980), juntamente com o baixo teor de enxofre.

Segundo Brito e Barrichello (1979), uma das mais importantes propriedades do combustível é o seu poder calorífico, o qual usualmente é obtido pela queima de uma quantidade conhecida de combustível, medindo-se o calor liberado. No caso de madeira pode-se encontrar valores desde 3000 $\mathrm{kcal} / \mathrm{kg}$ até $5400 \mathrm{kcal} / \mathrm{kg}$ com média de $4.200 \mathrm{kcal} /$ $\mathrm{kg}$, valores próximos aos encontrados no presente 
TABELA 2: Comparação de médias para poder calorífico superior (PCS), poder calorífico líquido (PCL), teor de umidade (TU) e teor de cinza (TC), dos diferentes resíduos avaliados.

TABLE 2: Comparison of mean values for calorific value (GCV), net calorific value (PCL), moisture content (TU) and ash content (TC) in different residues.

\begin{tabular}{c|c|c|c|c}
\hline Componente $^{1}$ & TU (\%) & TC (\%) & PCS (kcal/kg) & PCL (kcal/kg) \\
\hline Casca & $62 \mathrm{~b}$ & $14,74 \mathrm{a}$ & $4319 \mathrm{~b}$ & $1136 \mathrm{~b}$ \\
\hline Cavaco com casca & $54 \mathrm{~d}$ & $2,04 \mathrm{c}$ & $4690 \mathrm{a}$ & $1905 \mathrm{a}$ \\
\hline MIX & $57 \mathrm{c}$ & $4,40 \mathrm{~b}$ & $4520 \mathrm{ab}$ & $1732 \mathrm{a}$ \\
\hline $\begin{array}{c}\text { Serragem (recém- } \\
\text { gerada e de passivos } \\
\text { ambientais) }\end{array}$ & $66 \mathrm{a}$ & $0,85 \mathrm{c}$ & $4598 \mathrm{ab}$ & $1340 \mathrm{~b}$ \\
\hline
\end{tabular}

Em que: Médias seguidas pela mesma letra entre os componentes analisados (coluna) não diferem significativamente pelo teste de Tukey ao nível de $5 \%$ de probabilidade de erro. ${ }^{1}=$ Os resíduos denominados cavaco seco e o cavaco florestal não foram incluídos na análise em função do reduzido número de amostras.

trabalho. Os valores de poder calorífico superior (PCS) ficaram bastante próximos para todos os materiais. E, apesar da análise estatística ter indicado diferença entre os materiais, são consideradas significativas, em termos de desempenho da biomassa na geração de energia, somente diferenças no poder calorífico superiores a $300 \mathrm{kcal} / \mathrm{kg}$.

O cavaco com casca apresentou o maior PCS, mas não diferiu estatisticamente do MIX e da serragem. O poder calorífico éaltamente influenciado pela constituição química do material, ou seja, pela proporção de lignina, celulose e extrativos e também pela composição da biomassa em termos de quantidade de madeira e casca na amostra. Quanto maior for o teor de lignina e extrativos e menor o de celulose, maior o PCS do material. E, quanto maior a proporção de casca e menor a contaminação com compostos minerais incombustíveis, maior o poder calorífico.

Os valores de PCS para serragem e MIX não diferiram estatisticamente de casca e cavaco, pois estão em situação intermediária. Já a serragem, apesar de ser constituída basicamente de madeira, já havia sofrido decomposição, o que alterou as proporções de celulose, lignina, polioses e extrativos, reduzindo assim o poder calorífico em comparação com o cavaco. No MIX estavam presentes todos os materiais, e da mesma forma que para o teor de umidade, apresentou poder calorífico superior intermediário entre os valores dos materiais que o constitui.

Já a casca, por apresentar teores de cinza maiores que $12 \%$, teve poder calorífico superior mais baixo do que ocorreria se o teor de cinza fosse menor. Brand (2007) observou valores entre 4500 a $5000 \mathrm{kcal} / \mathrm{kg}$ para casca de Pinus com teores de cinza menores que $5 \%$.

$\mathrm{O}$ poder calorífico líquido (PCL) é a quantidade de energia realmente liberada e passível de utilização em um sistema de cogeração, ou seja, é igual ao PCS descontada a energia de vaporização necessária para eliminar a água presente no material, pois, segundo Brito e Barrichello (1979) a água tem um poder calorífico negativo, isto é, necessita-se de calor para evaporá-la.

O cavaco com casca e o MIX apresentaram valores significativamente superiores de PCL. Considerando que a planta que utilizou esta biomassa tem como parâmetro de processo o valor mínimo de poder calorífico líquido de $1900 \mathrm{kcal} / \mathrm{kg}$ para operação com eficiência, o cavaco com casca e o MIX foram os materiais que apresentaram melhor qualidade para o sistema de geração de energia.

O cavaco com casca teve o maior PCL em função de seus menores valores de teor de umidade e teor de cinza, pois estas duas propriedades têm influência inversa sobre o PCL, ou seja, quanto maior o teor de umidade e o teor de cinza, menor será o PCL (BRAND, 2007).

A serragem apresentou PCL reduzido devido ao elevado TU, não sendo recomendada para a geração de energia, de forma isolada. Outro aspecto negativo deste material é a sua reduzida granulometria e desuniformidade, o que prejudica o controle do processo e a eficiência da caldeira.

Já a casca teve baixo PCL devido ao elevado TC, porém, é o resíduo mais disponível para a queima. Deste modo, o tratamento da biomassa durante os processos de colheita, transporte, manuseio e manufatura industrial, visando à 
redução da contaminação por agentes minerais, é fundamental para o maior rendimento energético deste combustível.

\section{CONCLUSÕES}

- Os resíduos denominados casca de Pinus, cavaco com casca de Pinus, serragem, cavaco seco de Pinus e cavaco florestal foram os resíduos gerados, em maior quantidade, e destinados à produção de energia na região de Lages;

- A casca de Pinus teve a maior disponibilidade, seguido de cavaco com casca de Pinus e serragem, durante o período de análise considerado;

- Avaliando-se de forma conjunta as propriedades energéticas da biomassa, pode-se concluir que o cavaco com casca e o MIX foram os materiais mais eficientes energeticamente, pois apresentaram TU e TC mais baixos e maior PCL.

- A serragem teve limitações para a geração de energia devido ao elevado TU e granulometria desuniforme;

- Seria interessante desenvolver medidas que reduzissem o TC da casca, já que este foi o material mais utilizado para a geração de energia no período;

- O uso do MIX foi vantajoso, pois não ocorreram perdas significativas nas propriedades energéticas, melhorando as propriedades dos resíduos isoladamente.

\section{AGRADECIMENTOS}

À Tractebel Energia S.A., pelo apoio financeiro para a realização das atividades do projeto.

À EMBRAPA Florestas, pela concessão de bolsas para dois dos autores.

À Universidade do Planalto Catarinense UNIPLAC, pela utilização de suas dependências e concessão de bolsas a integrantes do grupo de pesquisa.

\section{REFERÊNCIAS BIBLIOGRÁFICAS}

ASSOCIAÇÃO BRASILEIRA DE NORMAS TÉCNICAS. NBR 13999: Papel, cartão, pastas celulósicas e madeira - Determinação do resíduo (cinza) após a incineração a $525{ }^{\circ} \mathrm{C}$. Rio de Janeiro, 2003.

ASSOCIAÇÃO BRASILEIRA DE NORMAS TÉCNICAS. NBR 14929: Madeira - Determinação do teor de umidade de cavacos - Método por secagem em estufa. Rio de Janeiro, 2003.

BRAND, M. A. et al. Análise da qualidade energética de resíduos madeiráveis ao longo de seis meses de armazenamento. In: CONGRESSO INTERNACIONAL DE BIOENERGIA,1., 2004, Campo Grande. Anais.... Campo Grande, 2004.

BRAND, M. A. Qualidade da biomassa florestal para o uso na geração de energia em função da estocagem. 2007, 169 f. Tese (PósGraduação em Ciências Florestais) - Universidade Federal do Paraná, Curitiba, 2007.

BRAND, M. A., et al. Caracterização da produção e uso dos resíduos madeiráveis gerados na indústria de base florestal da região serrana catarinense. UNIPLAC, Lages, Relatório técnico. 2001.

BRAND, M. A., et al. Caracterização do rendimento e quantificação dos resíduos gerados em serraria através do balanço de materiais. Revista Floresta, Curitiba, v. 32, n. 2, p. 247-259. 2002.

BRAND, M. A.; NEVES, M. D. Levantamento da disponibilidade dos resíduos industriais e florestais de madeira e avaliação da variação de sua qualidade energética em função das condições climáticas anuais, na região de Lages SC. UNIPLAC, Lages, Relatório técnico. 2005.

BRITO, J. O., BARRICHELO, L. E. G. Usos diretos e propriedades da madeira para geração de energia. Circular técnica, São Paulo, n. 52, jun.1979.

COELHO, S. T. Mecanismos para implementação da cogeração de eletricidade a partir da biomassa: Um modelo para o estado de São Paulo. 1999, 278 f. Tese (Doutorado em Energia - Programa Inter-unidades de Pós-Graduação em Energia) - Universidade de São Paulo, São Paulo, 1999.

DEUTSCHES INSTITUT FÜR NORMUNG e. V.

DIN 51900: Determining the gross calorific value of solid and liquid fuels using the bomb calorimeter, and calculation of net calorific value. Berlim, 2000. FURTADO, T. S., et al. Variáveis do processo de briquetagem e qualidade de briquetes de biomassa florestal. Pesquisa Florestal Brasileira, Colombo, v. 30, n. 62, p. 101-106, maio/jul. 2010.

MIGLIORINI, A. J. Densificação de biomassa florestal. Série Técnica IPEF, Piracicaba, v.1, n.2, p. C.1 - C.9, Jul.1980.

NOGUEIRA, L. A. H.; LORA, E. E. S. Dendroenergia: fundamentos e aplicações. 2. ed. Rio de Janeiro: Interciência, 2003.

SOARES, T. S. et al. Otimização de multiprodutos 
em povoamentos florestais. Revista Árvore, A. B. do. Avaliação econômica de um povoamento Viçosa, v. 27, n. 6, p. 811-820, 2003b. de Eucalyptus grandis destinado a multiprodutos. SOARES, T. S., CARVALHO, R. M. M. A., VALE, Revista Árvore, v. 27, n. 5, p. 689-694, 2003a. 